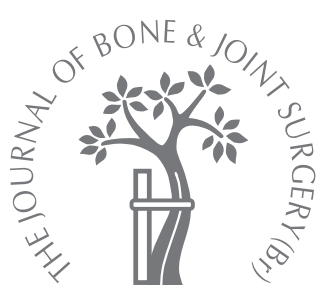

M. Khan, J.-H. Kuiper, J. B. Richardson

From The Robert Jones and Agnes Hunt Orthopaedic Hospital, Gobowen, England
M. Khan, MRCS, PhD Student, Clinical Research Fellow

In.-H. Kuiper, PhD, Lecturer in Biomechanics

I. B. Richardson, MD, FRCS, Professor of Orthopaedics Institute of Orthopaedics The Robert Jones and Agnes Hunt Orthopaedic Hospital, Gobowen, Shropshire SY10 7AG, UK.

Correspondence should be sent to Professor J. B. Richardson; e-mail:

Janet.Morris@ rjah.nhs.uk

(C)2008 British Editorial Society of Bone and Joint Surgery doi:10.1302/0301-620X.90B9. $20243 \$ 2.00$

$J$ Bone Joint Surg $[\mathrm{Br}]$ 2008;90-B:1152-7.

Received 24 September 2007;

Accepted after revision 29 April 2008

\section{The exercise-related rise in plasma cobalt levels after metal-on-metal hip resurfacing arthroplasty}

Contemporary metal-on-metal hip resurfacing has an excellent early to mid-term clinical outcome ${ }^{1-3}$ and is being used increasingly in young and active patients. ${ }^{4,5}$ The current results can be attributed largely to improved manufacture and a better understanding of its tribology. In vitro studies show low rates of wear ranging from $0.13 \mathrm{~mm}^{3} / \mathrm{MC}$ to $5 \mathrm{~mm}^{3} / \mathrm{MC}$ for hard metal-on-metal bearings of various diameters. ${ }^{6-10}$ These rates of wear are too small to be measured from radiographs. One method of determining in vivo wear is to measure the rate of release of wear debris from the bearing surfaces. The particles and ions produced, mainly cobalt and chromium are very small and are disseminated throughout the body. ${ }^{11}$ Their levels can be detected in the circulating blood and body fluids.

The rate of release of metal ions from functioning metal-on-metal bearings is not known. Two distinct phases of wear have been shown in in vitro studies. In the early phase, the wear rate is high as the bearing beds in. Later, the wear rate decreases and the bearing enters a steady-stage phase. Several simulator studies have shown this decline in wear rate with time. ${ }^{6-10}$ There is not, however, a corresponding fall in the level of metal ions in the blood. Several clinical studies ${ }^{12-16}$ have found that metal ion levels gradually rise with the passage of time from implantation.
Others ${ }^{17-19}$ have noted some decline. The reason for this gradual rise in metal ion levels is not known. If a failed metal-on-metal bearing is revised to a metal-on-polyethylene bearing the level of metal ions may remain elevated for up to two years. ${ }^{20}$ One possible explanation is that metal particles have a very long half-life in humans. The particles which have been deposited in distant organs may dissolve slowly and increase the levels of metal ions in the circulation. This would make circulating metal ion levels an inaccurate marker for in vivo wear. ${ }^{21}$

This effect may be avoided by measuring the exercise-related rise in the level of plasma cobalt. ${ }^{21}$ Exercise has been shown to cause an immediate rise in plasma metal ion levels in patients with a metal-on-metal bearing hip replacement. ${ }^{22}$ Cobalt is the predominant metal in the alloy used in the manufacture of metal-on-metal hip prostheses. The level of cobalt in the plasma does not fluctuate after exercise in patients who do not have a metallic implant, unlike the chromium level. ${ }^{22}$ Therefore, cobalt levels might more accurately reflect the in vivo behaviour of metal-onmetal bearings. We conducted this study to see whether the exercise-related rise $^{22}$ in plasma cobalt levels reflected the wear-in and steady-state wear of metal-on-metal hip resurfacing. 
Table I. Demographic data

\begin{tabular}{|c|c|}
\hline $\begin{array}{l}\text { Distribution of implant types by gender } \\
\text { Birmingham hip resurfacing }\end{array}$ & \\
\hline$M: F$ & $9: 6$ \\
\hline Cormet & \\
\hline $\mathrm{M}: \mathrm{F}$ & $4: 2$ \\
\hline Mean age in yrs (range) & 54 (38 to 80$)$ \\
\hline Mean height in $\mathrm{cm}$ (range) & 172 (137 to 187$)$ \\
\hline Mean weight in $\mathrm{kg}$ (range) & 82.7 (62 to 105$)$ \\
\hline Median femoral head size in $\mathrm{mm}$ (range) & $50 \quad(42$ to 54$)$ \\
\hline $\begin{array}{l}\text { Acetabular component inclination angle } \\
\left({ }^{\circ}\right) \text { (range) }\end{array}$ & 41 (29 to 70$)$ \\
\hline $\begin{array}{l}\text { Mean baseline plasma cobalt levels in } \mathrm{nmol} / \mathrm{l} \\
\text { (range) }\end{array}$ & 55 (14 to 144$)$ \\
\hline
\end{tabular}

\section{Patients and Methods}

Patients who had undergone a metal-on-metal resurfacing hip replacement were identified from the hospital records and invited to take part in the study. We excluded patients with inflammatory arthritis, a painful hip prosthesis, other metal implants, heart disease, renal failure, and a history of occupational exposure to cobalt and chromium. In total, 21 consecutive healthy patients were recruited (Table I). There were 13 men and eight women, with a mean age of 54 years (38 to 80). The Shropshire Research Ethics Committee and the Research Panel in our hospital approved the study. Each patient provided written consent.

Resurfacing arthroplasty implants and surgery. Two types of resurfacing were included in the study: the Birmingham Hip Resurfacing (BHR, Smith and Nephew, York, United Kingdom) and the Cormet 2000 Hip Resurfacing (Corin Medical, Cirencester, United Kingdom). The BHR is made from a high-carbon Co-Cr-Mo alloy and is used 'as cast'. The Cormet 2000 is also used 'as cast', but is heat treated using solution annealing and hot isostatic pressing. All the operations were undertaken by the senior author (JBR) using an anterolateral or posterior approach and a circumferential capsulotomy.

Exercise and blood collection. Each patient was asked to avoid strenuous activity in the week before the experiment. In particular, they were asked to avoid running, jogging, and attending fitness and gymnastic classes. The habitual activity level of each patient was recorded using the Tegner scale, ${ }^{23}$ which has 11 levels ( 0 is disabled and 10 is competitive sports level). Blood samples were taken from a forearm vein through a metal-free polypropylene cannula (Venflon, BD, Helsingborg, Sweden) which was left in the vein for subsequent blood sampling. The first $2 \mathrm{ml}$ to $5 \mathrm{ml}$ of each sample was discarded, a $2 \mathrm{ml}$ or $3 \mathrm{ml}$ blood sample was then collected in a metal-free lithium heparin tube (Teklab, Durham, United Kingdom). The first sample was collected before the patient started to exercise. They then walked or ran on a treadmill at their own pace for one hour in the hospital physiotherapy department. A pedometer
(Fit-Pro, I \& M Steiner, Brentford, United Kingdom) worn on the waist counted the number of steps taken. A second blood sample was taken immediately after exercise. A third sample was taken one hour after exercise. The samples were then centrifuged to isolate plasma.

Trace element analysis. All blood analysis was performed at the SAS Trace Metal Unit at Southampton General Hospital. Plasma cobalt was determined using inductivelycoupled plasma mass spectrometry (ICP-MS; Elan 6100 DRC plus-SCIEX, Perkin-Elmer, Beaconsfield, United Kingdom). The detection limit for cobalt in plasma was $1 \mathrm{nmol} / \mathrm{l}$

Acetabular inclination angle. The acetabular component inclination angle was measured on anteroposterior pelvic radiographs. The inclination angle was taken as an angle between the horizontal reference line (the line joining the inferior teardrop points) and the axis of opening of the acetabular component. All the measurements were done by the first author (MK).

Statistical analysis. All data were checked for a normal distribution. Data on plasma cobalt levels, exercise-related cobalt rise and acetabular component inclination angle were square root transformed to allow parametric testing. Independent $t$-tests were used to see whether male and female participants and groups based on either the BHR or Cormet implant differed in terms of age, weight, height, time since surgery, femoral head diameter, number of steps taken, baseline plasma cobalt levels and inclination of the acetabular component. Plasma cobalt levels before exercise were considered baseline, the highest levels after exercise were considered peak, and the difference between peak and baseline was considered the exercise-related cobalt rise. A paired $t$-test was used to compare baseline and peak levels. An independent $t$-test was used to compare the exerciserelated rise in cobalt levels between groups, based on gender and on either the BHR or Cormet implant types. Bivariate correlation analysis was used to check the relationship between two outcomes, baseline plasma cobalt levels and exercise-related cobalt rise, and potential predictors including gender, age, body weight, height, femoral head diameter, acetabular component inclination and number of steps. Stepwise multiple regression analysis was then performed to identify independent predictors of the baseline plasma cobalt levels and the exercise-related cobalt rise. Standardised beta $(\beta)$ values were calculated to determine a one SD change in the outcome variable as a result of one SD change in the predictor variable.

\section{Results}

The mean time from hip resurfacing to the exercise experiment was 44 months (10 to 96). The gender and implant (BHR/Cormet) groups were comparable in terms of age, height, weight, femoral head diameter, acetabular component inclination angle, time since surgery, activity level and pre-exercise plasma cobalt levels (Table II). Each patient was able to run or walk for one hour on a treadmill as 
Table II. Comparison of groups using independent $t$-tests

\begin{tabular}{|c|c|c|c|c|c|c|}
\hline & Male & Female & p-value & BHR $^{*}$ & Cormet & p-value \\
\hline Mean age in years (SD) & $55(11.5)$ & $52(6.6)$ & 0.53 & $55.3(10.8)$ & $50.6(6.5)$ & 0.78 \\
\hline Gender (M: F) & 13 & 8 & & 9:6 & $4: 2$ & \\
\hline Mean height in $\mathrm{cm}(\mathrm{SD})$ & 177 & (13) & 0.008 & $171.3(11.6)$ & $176.6(8.4)$ & 0.32 \\
\hline Mean weight in $\mathrm{kg}$ (SD) & $87 \quad(10.9)$ & (11.6) & 0.022 & $81.4(12.5)$ & $85.8(13.3)$ & 0.48 \\
\hline Tegner activity level ( 0 to 10$)$ & $4.8(3.1)$ & $4.6(2.9)$ & 0.63 & $4.3(2.5)$ & $4.7(3.2)$ & 0.74 \\
\hline $\begin{array}{l}\text { Mean acetabular component inclination angle } \\
\left({ }^{\circ}\right)(\mathrm{SD})\end{array}$ & $40 \quad(11.8)$ & $42 \quad(10.8)$ & 0.75 & $40 \quad(11)$ & $43 \quad(12)$ & 0.6 \\
\hline Mean number of steps (SD) & $7548 \quad(526)$ & $7186 \quad(418)$ & 0.11 & $7390 \quad(499)$ & $7462 \quad(580)$ & 0.77 \\
\hline Mean baseline plasma cobalt (nmol/l) (SD) & $48.8(35.8)$ & $64.7(36.8)$ & 0.34 & $50.2(31.7)$ & $66.7(46.6)$ & 0.35 \\
\hline Mean time since surgery (mths) (SD) & $37.7(27)$ & $54.3(26)$ & 0.184 & $46.8(29.2)$ & $37 \quad(23.2)$ & 0.47 \\
\hline Mean diameter of femoral head (mm) (SD) & $49 \quad(4)$ & $48 \quad$ (3) & 0.56 & $48 \quad(3.7)$ & $51 \quad(2.7)$ & 0.09 \\
\hline
\end{tabular}

* BHR, Birmingham Hip Resurfacing

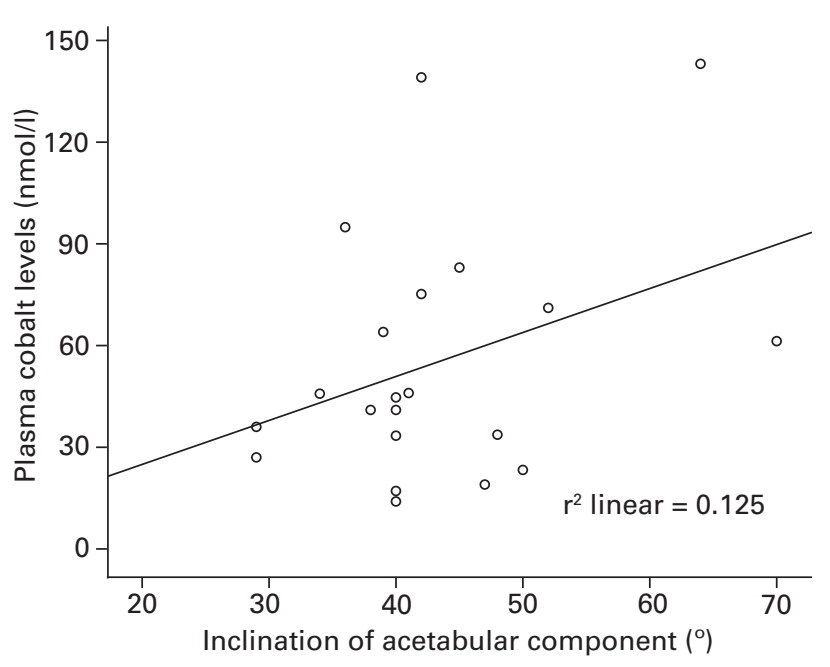

Fig. 1

Graph showing that baseline plasma cobalt levels increase with an increased angle of inclination of the acetabular component of a metalon-metal bearing hip resurfacing.

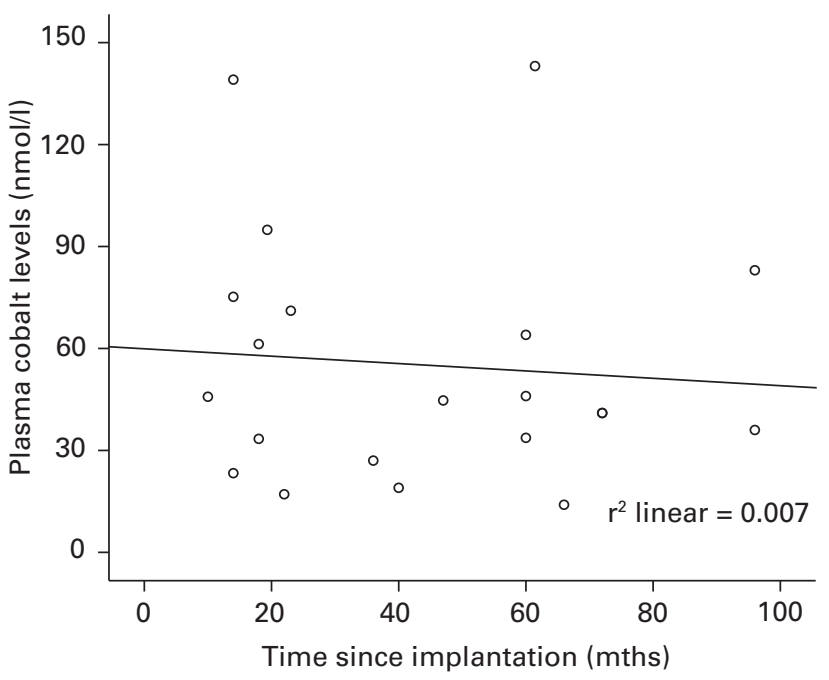

Fig. 2

Graph showing that baseline plasma cobalt levels do not significantly change with increasing time after implantation of a metal-on-metal bearing hip resurfacing. required. There was no significant difference in the mean number of steps taken by male or female patients ( $t$-est, $\mathrm{p}=0.11$ ) or by patients with different resurfacing implants ( $t$-test, $\mathrm{p}=0.77$ ) (Table II). A significant difference was noted in the mean baseline and mean peak plasma cobalt levels (paired $t$-test, $\mathrm{p}=0.001$ ). The mean rise in cobalt levels from the baseline was $4.5 \mathrm{nmol} / \mathrm{l}$ (SD 5.7) ( $8 \%$ ). This rise was similar for both men and women ( $t$-test, $\mathrm{p}=0.99)$. Patients with a BHR resurfacing had a mean increase in cobalt levels of $3.7 \mathrm{nmol} / \mathrm{l}$ (SD 5.9) (7\%), whereas patients with a Cormet 2000 resurfacing had a mean increase of $6.5 \mathrm{nmol} / \mathrm{l}(\mathrm{SD} 5.1)(12 \%)$ from baseline. This difference was not significant (independent $t$-test, $\mathrm{p}=0.28$ ). Baseline plasma cobalt levels were directly corre- lated with the inclination angle of the acetabular component $(\mathrm{r}=0.44, \mathrm{p}=0.404)$ (Fig. 1) but not significantly correlated with time since surgery $(r=-0.08, p=0.650)$; Fig. 2). The exercise-related rise in cobalt levels was directly correlated with the inclination angle of the acetabular component $(r=0.47, p=0.032$; Fig. 3$)$ and inversely correlated with time since surgery $(r=-0.5, p=0.020$; Fig. 4). Multiple stepwise regression analysis showed that the inclination angle of the acetabular component was the only statistically significant predictor of baseline plasma cobalt level (Table III). In contrast, time since surgery $(\mathrm{p}=0.034)$ and inclination of acetabular component $(p=0.040)$ were independent predictors of exercise-related cobalt rise (Table IV). Finally, we examined the results for a difference in the 


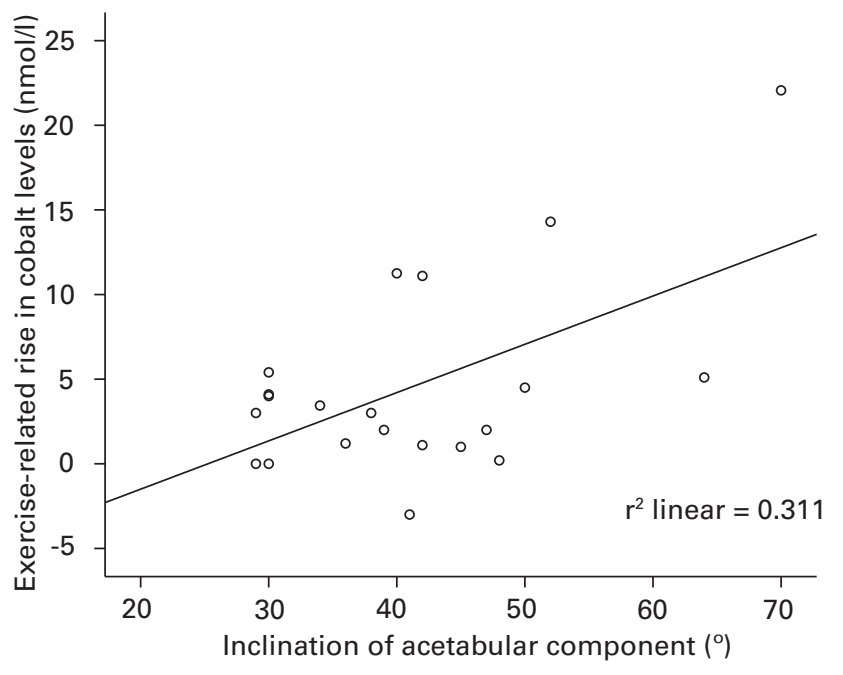

Fig. 3

Graph showing that an exercise-related rise in cobalt level increases with an increased angle of inclination of the acetabular component of a metal-on-metal bearing hip resurfacing.

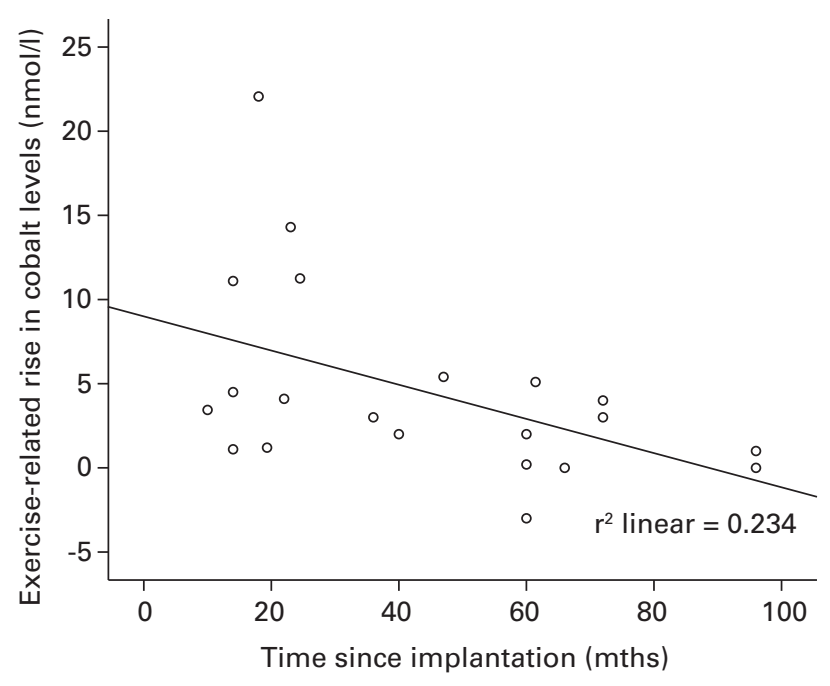

Fig. 4

Graph showing that an exercise-related rise in cobalt level decreases with time since implantation of a metal-on-metal bearing hip resurfacing.

Table III. Results of stepwise multivariate regression analysis of baseline plasma cobalt levels

\begin{tabular}{llll}
\hline & $\beta$ & Standard error $\beta$ & Standardised $\beta$ \\
\hline $\begin{array}{l}\text { Step } 1 \\
\text { Constant }\end{array}$ & 7.093 & 0.459 & \\
Inclination angle of the acetabular component & 1.26 & 0.584 & 0.44 \\
Inclination angle of the acetabular component & 0.056 & 0.020 & 0.467 \\
\hline
\end{tabular}

Plasma cobalt levels $R^{2}=0.19(p=0.044)$

Dependent variable: plasma cobalt levels

exercise-related cobalt rise between the two types of implant, with time since surgery and acetabular component inclination angle as independent predictor variables. The type of prosthesis had no effect on the exercise-related cobalt rise $(\beta=0.368, p=0.416)$.

In the study two patients had identical pre- and postexercise cobalt levels, and a third patient had lower postexercise cobalt levels than the pre-exercise level. All these patients had BHR prostheses and their time since implantation was in excess of the mean period, ranging from five to eight years. Their acetabular inclination angle was below the mean value of $40^{\circ}$, ranging from $29^{\circ}$ to $70^{\circ}$.

\section{Discussion}

This study shows that physiological exercise in patients with a resurfacing hip prosthesis causes a significant rise in plasma cobalt levels. The mean cobalt ion levels rose by $4.5 \mathrm{nmol} / \mathrm{l}$ $(8 \%)$ within one hour of completing one hour of exercise. It also shows that patients whose implant has been in place for a longer time have a smaller rise in cobalt levels in response to exercise. In contrast, the baseline plasma cobalt levels did not decrease with a longer period of implantation. The inclination angle of the acetabular component was another important predictor of cobalt ion levels, as a greater inclination angle produced a significant increase in exercise-related and baseline plasma cobalt levels.

Wear rates have been shown to decline to a much lower level once a bearing beds in and enters a steady state. ${ }^{6-10}$ If the metal ion levels truly reflect wear rates, they should decline over time. In our study, plasma cobalt levels were not affected by the time since implantation of the resurfacing hip arthroplasty. This finding suggests that plasma cobalt levels do not mirror the pattern of wear expected from in vitro studies. However, the rise in exercise-related plasma cobalt level was significantly associated with time since implantation of the resurfacing arthroplasty, with an increasing time since implantation producing a smaller rise in cobalt levels. This is more consistent with the pattern of wear expected from in vitro studies, suggesting that the exercise-related rise in cobalt levels may be a better in vivo marker of wear. 
Table IV. Results of stepwise multivariate regression analysis of exercise-related plasma cobalt levels

\begin{tabular}{llll}
\hline & $\beta$ & Standard error $\beta$ Standardised $\beta$ \\
\hline Step 1 & & & \\
$\quad$ Constant & 2.92 & 0.33 & -0.56 \\
$\quad$ Time since surgery & -0.024 & 0.008 & \\
& & & -0.49 \\
Step 2 & 2.6 & 0.427 & 0.467 \\
$\quad$ Constant & -0.021 & 0.007 & 0.020 \\
$\quad$ Time since surgery & 0.056 & & \\
$\quad$ Inclination angle of the acetabular component & & & \\
\hline
\end{tabular}

$\mathrm{R}^{2}=0.31$, for Step 1 ; and $\mathrm{R}^{2}=0.52$ for Step $2(\mathrm{p}=0.020)$

Acetabular component inclination angle was centred to the mean

Dependent variable: exercise-related rise in cobalt levels

The rise in cobalt levels was negligible in those patients whose resurfacing hip replacement had been implanted for a longer time. This suggests that fewer wear particles were being generated in these patients and that the metal ion levels would slowly fall in the long term. As a result, the risk of cancer and cytotoxicity will also decrease as the exposure to particulate debris decreases.

A rise in metal ion levels resulting from increased activity was first detected by Gleizes et al in $1999 .{ }^{24}$ We have confirmed this observation by finding a significant rise in cobalt levels following an hour of exercise. This required precise measurement of the metal ion level, as the increase may be as small as $10 \%$ of the resting value. In a previous study $^{22}$ we found that there was also a rise in plasma chromium levels after exercise in patients who had no metallic implants in their bodies. Therefore, we suggest that only exercise-related cobalt levels are measured as an in vivo measure of metal-on-metal bearing wear.

In contrast to the present study and two earlier reports, ${ }^{22,24}$ two further studies ${ }^{25,26}$ have failed to find a significant rise in cobalt levels after strenuous activity. This may be the result of differences in the techniques of measuring the metal ion levels. Additionally, De Haan et $\mathrm{al}^{26}$ collected their serum sample on the day after exercise, by which time the metal ions could have returned to their preexercise levels.

Higher serum cobalt levels have been reported previously in patients whose acetabular component was included more than $60^{\circ} .{ }^{27}$ We found a correlation between the exercise rise in cobalt levels that extended into the normal range of acetabular inclination angle. This rise was not seen with an inclination angle below the mean value. Accordingly, we recommend implanting the acetabular component with an inclination angle of $40^{\circ}$ or less to minimise the release of wear debris.

We found no significant difference in the exercise-related cobalt rise between patients with BHR and Cormet resurfacing prostheses, but recognise that this may be a function of the small numbers in our study.

In conclusion, we found that exercise causes a rise in plasma cobalt levels in patients who have a metal-on-metal resurfacing hip replacement. This is greatest in the early post-operative period but decreases to an almost negligible level with time. Resting plasma cobalt levels do not show this behaviour.

No benefits in any form have been received or will be received from a commercial party related directly or indirectly to the subject of this article.

\section{References}

1. Daniel J, Pynsent PB, McMinn DJ. Metal-on-metal resurfacing of the hip in patients under the age of 55 years with osteoarthritis. J Bone Joint Surg [Br] 2004;86B:177-84.

2. Treacy RB, McBryde CW, Pynsent PB. Birmingham hip resurfacing arthroplasty: a minimum follow-up of five years. J Bone Joint Surg [Br] 2005;87-B:167-70.

3. Steffen RT, Pandit HP, Palan J, et al. The five-year results of the Birmingham Hip Resurfacing arthroplasty: an independent series. J Bone Joint Surg [Br] 2008;90B:436-41.

4. White SP, Beard DJ, Smith EJ. Resurfacing hip replacement: an audit of activity in the United Kingdom 2002-2003. Hip International 2004;14:163-8.

5. Pollard TCB, Baker RP, Eastaugh-Waring SJ, Bannister GC. Treatment of the young active patient with osteoarthristis of the hip: a five- to seven-year comparison of hybrid total hip arthroplasty and metal-on-metal resurfacing. J Bone Joint Surg [Br] 2006;88-B:592-600.

6. Firkins PJ, Tipper JL, Saadatzadeh MR, et al. Quantitative analysis of wear and wear debris from metal-on-metal hip prostheses tested in a physiological hip joint simulator. Biomed Mater Eng 2001;11:143-57.

7. Chan FW, Bobyn JD, Medley JB, Krygier JJ, Tanzer M. Wear and lubrication of metal-on-metal hip implants. Clin Orthop 1999;369:10-24.

8. Scholes SC, Green SM, Unsworth A. The wear of metal-on-metal total hip prostheses measured in a hip simulator. Proc Inst Mech Eng [H] 2001;215:523-30.

9. Smith SL, Dowson D, Goldsmith AA. The effect of femoral head diameter upon lubrication and wear of metal-on-metal total hip replacements. Proc Inst Mech Eng [H] 2001;215:161-70.

10. Goldsmith AA, Dowson D, Isaac GH, Lancaster JG. A comparative joint simulator study of the wear of metal-on-metal and alternative material combinations in hip replacements. Proc Inst Mech Eng [H] 2000;214:39-47.

11. Case CP, James VG, Palmer MR, et al. Widespread dissemination of metal debris from implants. J Bone Joint Surg [Br] 1994;76-B:701-12.

12. Brodner W, Bitzan $\mathbf{P}$, Meisinger V, et al. Elevated serum cobalt with metal-onmetal total hip arthroplasty. J Bone Joint Surg [Br] 1997;79-B:316-21.

13. Brodner W, Bitzan $P$, Meisinger V, et al. Serum cobalt levels after metal-on-metal total hip arthroplasty. J Bone Joint Surg [Am] 2003;85-A:2168-73.

14. Schaffer AW, Pilger A, Engelhardt C, Zweymueller K, Ruediger HW. Increased blood cobalt and chromium after total hip replacement. J Toxicol Clin Toxicol 1999;37:839-44.

15. Savarino L, Granchi D, Ciapetti G, et al. Ion release in stable hip arthroplasties using metal-on-metal articulating surfaces: a comparison between short- and medium-term results. J Biomed Mater Res A 2003;66:450-6.

16. Vendittoli P-A, Mottard S, Roy AG, Dupont C, Lavigne M. Chronium and cobalt ion release following the Durom high carbon content, forged metal-on-metal surface replacement of the hip. J Bone Joint Surg [Br] 2007;89-B:441-8.

17. Back DL, Young DA, Shimmin AJ. How do serum cobalt and chromium levels change after metal-on-metal hip resurfacing? Clin Orthop 2005;438:177-81. 
18. Skipor AK, Campbell PA, Patterson LM, et al. Serum and urine metal levels in patients with metal-on-metal surface arthroplasty. J Mater Sci Mater Med 2002:13:1227-34.

19. Daniel J, Ziaee H, Pradhan C, Pynsent PB, McMinn DJW. Blood and urine meta ion levels in young and active patients after Birmingham hip resurfacing arthroplasty: four-year results of a prospective longitudinal study. J Bone Joint Surg [Br] 2007;89 B:169-73

20. Milosev I, Pisot V, Campbell P. Serum levels of cobalt and chromium in patient with Sikomet metal-metal total hip replacements. J Orthop Res 2005;23:526-35.

21. Khan M, Kuiper J, Richardson JB. Can cobalt levels estimate in-vivo wear of metal on metal bearings used in hip arthroplasty? Proc Inst Mech Engh [H] 2007:221:929-42.

22. Khan M, Takahashi T, Kuiper JH, et al. Current in vivo wear of metal-on-metal bearings assessed by exercise-related rise in plasma cobalt level. J Orthop Res 2006;24:2029-35.
23. Tegner Y, Lysholm J. Rating systems in the evaluation of knee ligament injuries. Clin Orthop 1985;198:43-9.

24. Gleizes V, Poupon J, Lazennec JY, Chamberlin V, Saillant G. Value and limits of determining serum cobalt levels in patients with metal on metal articulating prostheses. Rev Chir Orthop Reparatrice Appar Mot 1999;85:217-25 (in French).

25. Heisel C, Silva M, Skipor AK, Jacobs JJ, Schmalzried TP. The relationship between activity and ions in patients with metal-on-metal bearing hip prostheses. $J$ Bone Joint Surg [Am] 2005;87-A:781-7.

26. De Haan R, Campbell P, Reid S, Skipor AK, De Smet K. Metal ion levels in a triathlete with a metal-on-metal resurfacing arthroplasty of the hip. J Bone Joint Surg [Br] 2007;89-B:538-41.

27. Brodner W, Grubl A, Jankovsky R, et al. Cup inclination and serum concentration of cobalt and chromium after metal-on-metal total hip arthroplasty. J Arthroplasty 2004;19(Suppl 3):66-70. 